\title{
Preparation of Zinc(II) Phthalocyanine-Based LB Thin Film: Experimental Characterization, the Determination of Optical Properties and Harmful Organic Vapor Sensing Ability
}

Yaser Acikbas ( $\square$ yaser.acikbas@usak.edu.tr )

University of Usak https://orcid.org/0000-0003-3416-1083

Matem Erdogan

Balikesir University: Balikesir Universitesi

Rifat Capan

Balikesir University: Balikesir Universitesi

Cansu Ozkaya

Balikesir University: Balikesir Universitesi

Yasemin Baygu

Pamukkale Üniversitesi: Pamukkale Universitesi

Nilgün Kabay

Pamukkale Üniversitesi: Pamukkale Universitesi

Yaşar Gök

Usak University: Usak Universitesi

\section{Research Article}

Keywords: Zn(II)phthalocyanine, Langmuir-Blodgett films, SPR, QCM, optical materials and properties, sensors.

Posted Date: March 2nd, 2021

DOl: https://doi.org/10.21203/rs.3.rs-235581/v1

License: (c) (1) This work is licensed under a Creative Commons Attribution 4.0 International License. Read Full License 


\section{Abstract}

Zinc(II) phthalocyanine (Zn(II)Pc) molecule was the first time prepared onto three different substrates utilizing Langmuir-Blodgett (LB) deposition technique to investigate its vapor sensing abilities and some optical properties. We utilized five different and well-known techniques to control monolayer quality of $\mathrm{Zn}$ (II)Pc LB film. The obtained the thickness and refractive index values for $\mathrm{Zn}$ (II)Pc LB film with coated at different layers vary from 3.2 to $10.9 \mathrm{~nm}$ and from 1.42 to 1.71 , respectively. The sensing properties were investigated by exposing the Zn(II)Pc-based mass or optical sensor to some organic vapors. Kinetic results presented that this $\mathbf{Z n}$ (II)Pc material is a good candidate as a sensor element with a fast and reversible response for dichloromethane sensing devices.

\section{Introduction}

Phthalocyanines have been greatly preferred in many technological and scientific areas such as solar cells [1], LB films [2] and chemical sensors [3]. Presence of planar delocalized large 18 $\pi$ electrons in the macrocycle and strong optical absorption in metallo phthalocyanines provide them a convenient sensing material for volatile organic compounds (VOCs) [4]. LB thin film technique plays a critical role to fabricate a sensitive thin film layer of phthalocyanine derivative for room temperature VOCs sensor applications due to its practical and controlled production [5]. Surface plasmon resonance (SPR) and quartz crystal microbalance (QCM) methods are widely utilized as an optical sensitive and mass sensitive, respectively, for the VOCs detection using phthalocyanine LB films [6,7]. Thanks to the high sensitivity and stability of the sensitive absorption layers, phthalocyanine-based thin films have become a significant area of study in sensor applications [8].

In this paper, a new synthesized amphiphilic phthalocyanine ( $\mathrm{Zn}(\mathrm{II}) \mathrm{Pc})$ is selected to fabricate a sensitive and selective LB thin film layer which is used for a detection of VOCs. Dichloromethane, carbon tetrachloride, toluene and $\mathrm{m}$-xylene vapors are used for sensor applications. SPR and QCM results indicated that the selectivity of $\mathbf{Z n}$ (II)Pc LB layer to dichloromethane is approximately 3.39 times for SPR and 2.69 times for QCM results higher than other vapors. The results obtained from kinetic results stated that Zn(II)Pc-based mass or optical sensor yields a stable and reversible response to all vapors and a selective and sensitive response to dichloromethane vapor than others.

\section{Experimental Details}

$\mathrm{Zn}$ (II)Pc molecule (Fig. 1), which is a candidate for the use of a sensor active layer, was synthesized by the following literature [9]. All Zn(II)Pc thin films were prepared with model 622 Nima-LB trough (area $1200 \mathrm{~cm}^{2}$ ) onto three different substrates such as gold-coated glass, quartz glass and quartz crystal for SPR, UV-Vis, SEM, AFM and QCM measurements.

The properties of Langmuir for Zn(II)Pc molecules were examined using a NIMA 622 model LB trough. The surface pressure ( $\pi$ ) measurements as a function of the area (A) covered by the $\mathbf{Z n}(\mathrm{II}) \mathrm{Pc}$ molecules 
dissolved in chloroform. This solution at a concentration of $1 \mathrm{mg} \mathrm{mL}^{-1}$ was slowly dripped into the trough, whose water surface was controlled for cleanliness $(0<\pi>0.1)$, using microliter syringe (Hamilton). The LB trough (made of Teflon materials) consists of Wilhelmy, which is used as a pressure sensor, and two barriers, one of which is movable. This barrier compression speed has been determined in the literature to be a suitable value to avoid instability effects [10-12]. After waiting approximately 15 minutes for the chloroform in solution to evaporate, the moving barrier was allowed to compress the monolayer at the air / water interface towards the center of the trough. Isotherms obtained as a result of compression of the Langmuir monolayer at the air / water interface are characterized by certain regions such as gas phase, liquid phase, solid phase and collapse. The process of all $\mathbf{Z n ( I I ) P c ~ L B ~ l a y e r ~ d e p o s i t i o n ~}$ was fixed by determining a convenient surface pressure value of $25 \mathrm{mN} \mathrm{m}^{-1}$ from isotherm graph (Fig. S1).

The process of $\mathbf{Z n ( I I ) P c ~ L B ~ l a y e r ~ d e p o s i t i o n ~ o n t o ~ s o l i d ~ s u b s t r a t e s ~ w a s ~ s t a r t e d ~ a f t e r ~ t h e ~ d e t e r m i n a t i o n ~ o f ~ a ~}$ suitable surface pressure. LB thin film transfer curve is a critical parameter for monitoring the deposition process, and the first four layer transfer graph of $\mathrm{Zn}(\mathrm{II}) \mathrm{Pc}$ monolayer within the scope of the paper is given in Fig. 2. The analysis of this process is carried out by calculating the transfer rate (TR) shown in Equation 1.

$\mathrm{TR}=\frac{\mathrm{A}_{1}}{\mathrm{~A}_{2}}$

$A_{1}$ is the decrease in the area covered by a monolayer on the water surface and $A_{2}$ is the area of the thin film coated on the substrate. The TR value was calculated as $\sim 0.93$ for $\mathbf{Z n}$ (II)Pc LB thin film. This value is proof that homogeneous LB thin films have been successfully produced.

The chemical sensing abilities of Zn(II)Pc LB thin film sensor were actualized via SPR and QCM technique. The detailed information about these techniques was reported in the part of Supplementary Data (Fig. S2).

\section{Results And Discussion}

\subsection{UV-Visible Results}

The absorption spectra of $\mathbf{Z n ( I I ) P c}$ chloroform solution using different concentration and $\mathbf{Z n ( I I ) P c ~ L B ~ t h i n ~}$ film multilayers prepared onto quartz glass substrate was obtained by UV-vis spectrometer and results represented in Fig. S3 and Fig. 3, respectively. Two absorption bands attributed to $\pi-\pi^{\star}$ transition (the Soret (B) and the Q-band) of the Zn(II)Pc molecules were observed at $269 \mathrm{~nm}$ and $684 \mathrm{~nm}$ both $\mathbf{Z n}$ (II)Pc solution and LB thin film multilayers. The inset in Fig. 3 shows the correlation between number of layers and the change of absorption values. This linear proportionality between them has supported that deposition takes place during coating for each layer and coating is very sustainable for each bilayer.

\subsection{QCM results}


In this work, the Y-type Zn(II)Pc LB films were fabricated in a symmetrical mode onto quartz crystal substrate (Fig. 4). The inset in Fig. 4 presents linearity between the frequency change and Zn(II)Pc LB layers with a linear regression of 0.9923 . This linearity demonstrated that each $\mathbf{Z n}(\mathrm{II}) \mathrm{Pc}$ bilayer could be successfully deposited and almost equal mass was coated onto the substrate. The frequency change for each layer $(27.17 \mathrm{~Hz} /$ layer) and the mass coated onto the substrate for each layer (435.124 ng/layer) could be determined from the data of the inset in Fig. 4 and by utilizing Sauerbrey equation [13].

\subsection{SPR results}

SPR system was utilized to evidence the deposition of $\mathbf{Z n ( I I ) P c ~ L B ~ m o n o l a y e r ~ o n t o ~ g o l d - c o a t e d ~ s u b s t r a t e . ~}$ The SPR curves of $\mathbf{Z n ( I I ) P c ~ L B}$ thin films are represented in Fig. S4 and these curves (from 2 layers to 10 layers) shift to from the left to the right. The inset in Fig. S4 presents the linear relationship between the shifts in the angle of incidence and Zn(II)Pc LB layers. A linear regression of 0.9884 indicates that $\mathrm{Zn}$ (II)Pc LB films were fabricated onto the substrate successfully and homogenously. The experimentally measured SPR curves of Zn(II)Pc LB films were fitted via Winspall software to determine the values of refractive index and thickness for $\mathbf{Z n}$ (II)Pc-coated thin films. The fitted SPR curves for Zn(II)Pc-coated four LB film layers and bare gold were given in Fig. 5. Similar fitting process was fixed for other Zn(II)Pc LB layers. The inset in Fig. 5 provided similar results compared with UV-Vis and QCM results by obtaining of the linear relationship. As seen in Table 1 and the inset of Fig. 5, the values of $\mathbf{Z n ( I I ) P c ~ L B ~ f i l m ~}$ thickness or refractive index demonstrate a rise depending on the $\mathrm{Zn}$ (II)Pc LB layers.

Table 1 The thickness and refractive index of $\mathrm{Zn}(\mathrm{II}) \mathrm{Pc}$ thin films.

\begin{tabular}{|llll|}
\hline & Number of LB layers & Thickness $(\mathrm{nm})$ & Refractive index \\
\hline \multirow{2}{*}{$\begin{array}{l}\text { Zn(II)Pc } \\
\text { LB thin film }\end{array}$} & 2 layer & 3.2 & 1.41 \\
\cline { 2 - 4 } & 4 layer & 5.6 & 1.53 \\
\cline { 2 - 4 } & 6 layer & 7.4 & 1.61 \\
\cline { 2 - 4 } & 8 layer & 9.5 & 1.66 \\
\hline 10 layer & 10.9 & 1.72 \\
\hline
\end{tabular}

\subsection{AFM and SEM results}

AFM measurements were taken to analyze the surface morphology of $\mathrm{Zn}(\mathrm{II}) \mathrm{Pc}$ LB thin film with 2D and 3D AFM images in the surface area of $10 \times 10 \mu \mathrm{m}^{2}$ (Fig. 6). The RMS roughness, mean roughness and maximum height values of the surface were observed as $3.8,2.85$ and $14.96 \mathrm{~nm}$ for the image recorded with the dimensions $10 \mu \mathrm{m} \times 10 \mu \mathrm{m}$, respectively. The Zn(II)Pc LB film surfaces, containing some roughness structure, provide VOCs molecules to penetrate into deeper layer in vapor sensing application. 
SEM images of non-coated bare glass and Zn(II)Pc LB film coated glass were obtained for the supporting of the LB films fabricated. While Fig. S5a displays the SEM image for bare glass (non-coated), the SEM image given in Fig. S5b proves the matrix of $\mathrm{Zn}(\mathrm{II}) \mathrm{Pc}$ can be formed in the thin film.

\subsection{Kinetic Measurements of the Optical/Mass Chemical Sensor}

SPR technique is used to monitor a host-guest interaction between the $\mathrm{Zn}$ (II)Pc-based chemical sensor and VOCs by recording the photodetector responses (Fig. 7). Some harmful VOCs, namely, toluene, mxylene, carbon tetrachloride and dichloromethane were released into the space of gas cell for 120 seconds, in order of air-vapor-air-vapor-...-air, periodically. The responses of LB film to all vapors suddenly increased by several seconds (adsorption process) and then an exponential decrease was observed due to the diffusion process. This rapid change can be resulted from two important reasons. The first, the shift of background refractive index, which depends on the concentration of vapor, may be asserted. The surface effect between Zn(II)Pc LB film surface and vapor molecules can be stated as the second reason. Similar kinetic study was carried out using QCM technique for supporting SPR kinetic results. From the Fig. 7 and Fig. S6, the comparatively large response values obtained from SPR and QCM measurements for dichloromethane are noteworthy among used vapors at saturated concentration. The SPR/QCM kinetic results of the $\mathbf{Z n ( I I ) P c - b a s e d ~ c h e m i c a l ~ s e n s o r ~ t o ~ d i c h l o r o m e t h a n e ~ v a p o r ~ w a s ~ p r e s e n t e d ~ i n ~ F i g . ~ S 7 ~}$ and Fig. S8 to observe the repeatability and renewability properties of Zn(II)Pc LB film chemical sensor by running three times of this process. These kinetic results show that $\mathbf{Z n}(\mathrm{II}) \mathrm{Pc}$ chemical sensor are reproducible for dichloromethane vapor. Similar the host-guest interaction was recorded at different concentration of dichloromethane represented in Fig. S9.

The results of all kinetic measurements can be expressed through the vapor pressure and the molar volume of VOCs given in Table 2 , and dichloromethane vapor has the biggest vapor pressure $\left(\right.$ at $20^{\circ} \mathrm{C}$ ) and molar volume among used in this work. Since dichloromethane molecules have the highest vapor pressure and the lowest molar volume among VOCs used in this work, their diffusions into the Zn(II)Pc LB film is the easiest. The values of the kinetic responses for the other vapors (carbon tetrachloride, toluene and $m$-xylene) are lower than dichloromethane vapor due to the effect of these physical properties. Therefore, the other vapors with the highest molar volume cannot easily penetrate into the $\mathrm{Zn}$ (II)Pc LB thin film sensor material when compared with the diffusion of dichloromethane vapor into the same thin film.

Table 2 Physical properties of organic vapors and kinetic responses. 


\begin{tabular}{|lllll|}
\hline Organic vapors & $\begin{array}{l}\text { Molar } \\
\text { volume } \\
\left(\mathrm{cm}^{3} \mathbf{~ m o l}^{-1}\right)\end{array}$ & $\begin{array}{l}\text { Vapor pressure }(\mathrm{kPa}, \mathbf{2 0} \\
\left.{ }^{-1} \mathrm{C}\right)\end{array}$ & $\begin{array}{l}\text { Photodetector } \\
\text { response change, } \\
(\Delta \mathrm{l})\end{array}$ & $\begin{array}{l}\text { Frequency } \\
\text { shift, } \\
(\Delta \boldsymbol{f})\end{array}$ \\
\hline Dichloromethane & 64.10 & 46.50 & 0.148 & 78 \\
\hline $\begin{array}{l}\text { Carbon } \\
\text { tetrachloride }\end{array}$ & 97.10 & 12.00 & 0.044 & 29 \\
\hline Toluene & 107.10 & 2.91 & 0.037 & 27 \\
\hline m-xylene & 122.00 & 0.80 & 0.016 & 24 \\
\hline
\end{tabular}

\section{Conclusions}

The structural characterization and the preparation quality of Zn(II)Pc LB thin film layers were examined by (i) the mass change onto quartz crystal (ii) the shift of the UV-Vis absorption spectra (iii) the change of resonance angle in the SPR curves, and (iv) SEM/AFM imaging techniques. The results obtained from all characterization techniques aforementioned in related parts prove that the fabrication of $\mathbf{Z n}$ (II)Pc-based thin films onto the different substrates was successfully and uniformly achieved with linear regressions vary from 0.9884 to 0.9957 . Some optical properties of $\mathrm{Zn}$ (II)Pc materials were also illuminated with this study. The sensing behaviors of $\mathbf{Z n ( I I ) P c}$ chemical sensor against to some VOCs were investigated by utilizing QCM and SPR techniques. These kinetic results present that Zn(II)Pc-coated chemical sensor exhibits higher sensitive and selective response to dichloromethane vapor than other vapors.

\section{References}

1. Yıldız, E. Güzel, N. Menges, İ. Şişman, M.K. Şener, Sol. Energy 174, 527 (2018)

2. Gu, J.Yin, P. Liang, F. Gan, Opt. Mater. 27(10), 1618 (2005)

3. E. Duran, I. Capan, Surf. Rev. Lett. (2020) doi:10.1142/S0218625X20500067.

4. Fietzek, K. Bodenhöfer, M. Hees, P. Haisch, M. Hanack, W. Göpel, Sens. Actuators B: Chem. 65, 85 (2000)

5. Capone, S. Mongelli, R. Rella, P. Siciliano, L. Valli, Langmuir 15, 1748 (1999)

6. Rella, A. Rizzo, A. Licciulli, P. Siciliano, L. Troisi, L. Valli, Mater. Sci. Eng. C 22, 439 (2002)

7. Harbecka, O.F. Emirik, I. Gurol, A.G. Gurek, Z.Z. Ozturk, V. Ahsen, Sens. Actuators B: Chem. 176, 838 (2013)

8. İ. Çapan, B. İlhan, J. Optoelectron. Adv. Mater. 17, 456 (2015)

9. Baygu, T. Sogancı, N. Kabay, Y. Gök, M. Ak, Mater. Today Chem. 18, 100360 (2020)

10. F. Hifeda, G.W. Rayfield, Evidence for First-Order Phase Transitions in Lipid and Fatty Acid Monolayers, Langmuir. 8, 197 (1992)

11. R. Arriaga, I. Löpez-Montero, J. Ignés-Mullol, F. Monroy, J. Phys. Chem. B. 114, 4509 (2010) 
12. Guzmán, E. Santini, M. Ferrari, L. Liggieri, F. Ravera, Langmuir. 33, 10715 (2017)

13. Sauerbrey, Z. Physik 155, 206 (1959)

Figures

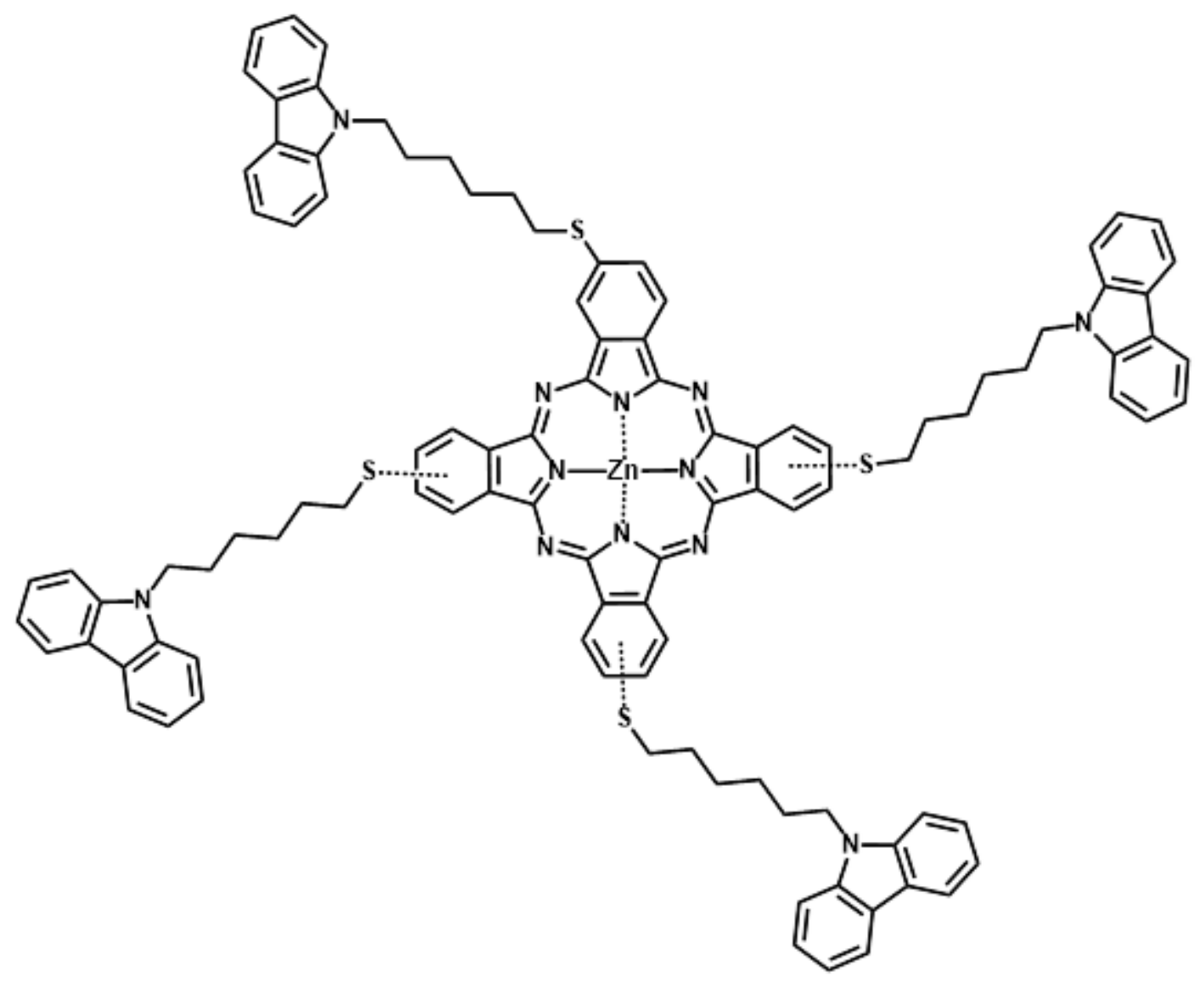

Figure 1

The molecular structure of the Zn(II)Pc. 


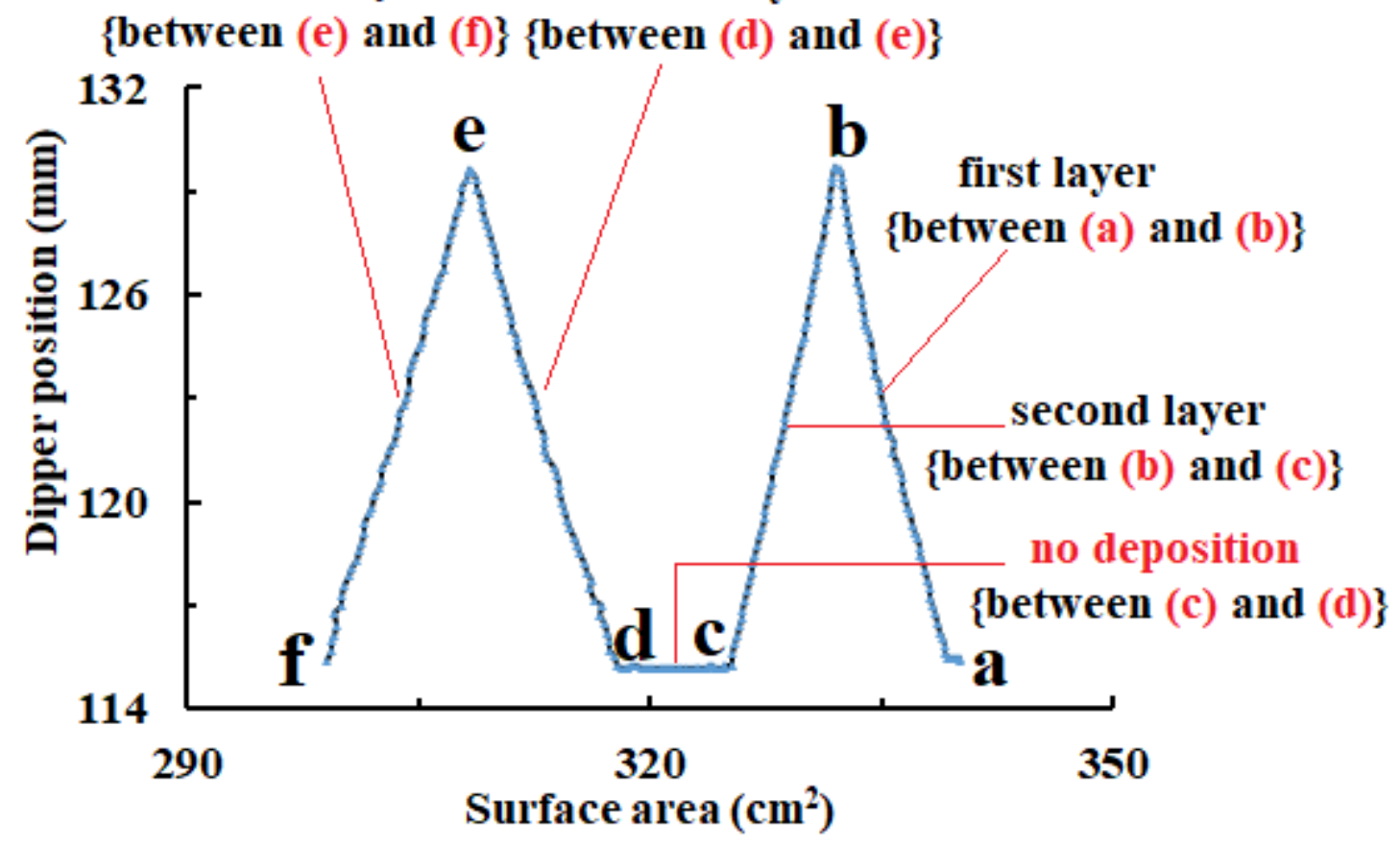

Figure 2

The deposition graph of Zn(II)Pc LB thin film onto a gold-coated glass substrate.

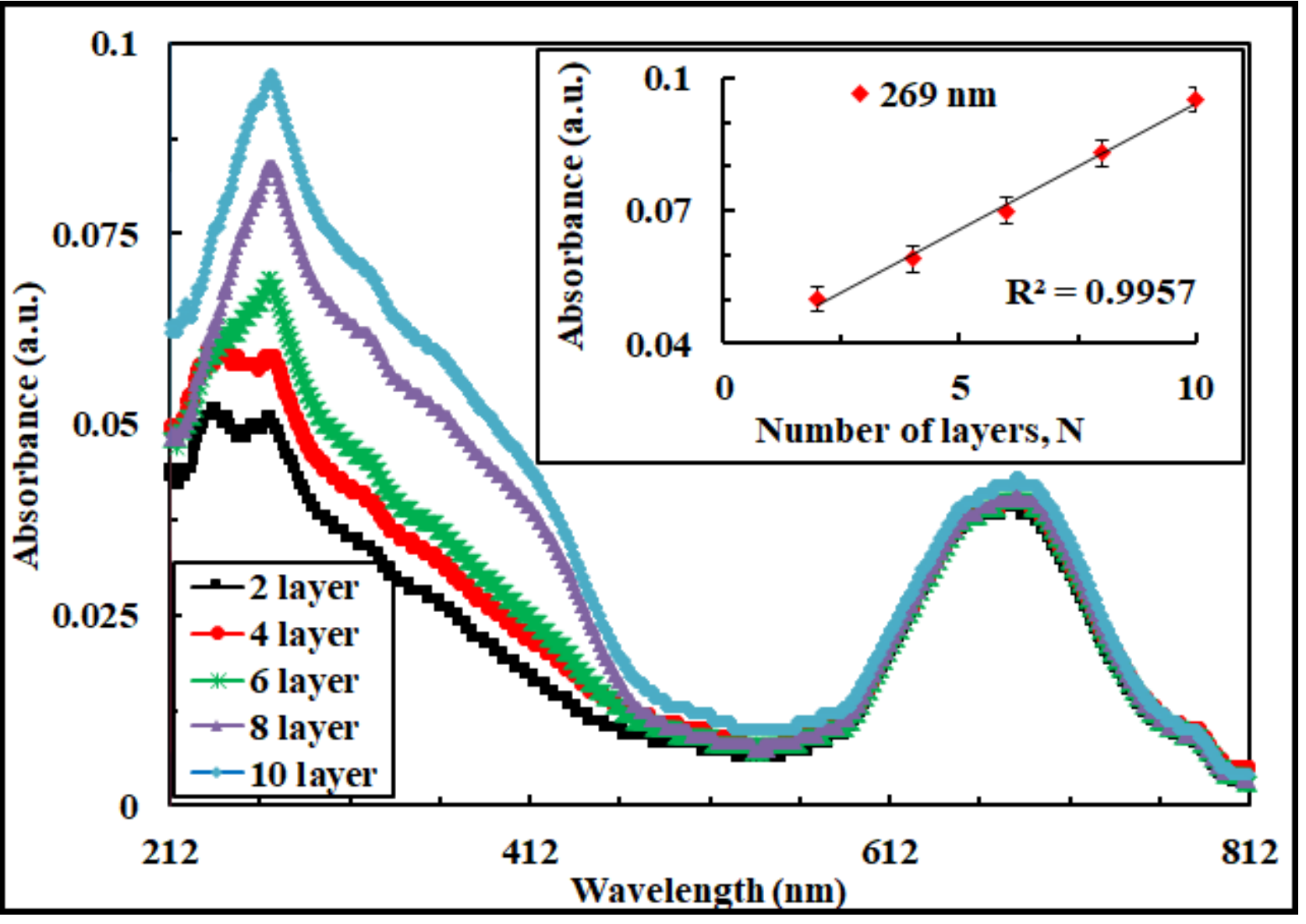

Figure 3 
UV-Vis results for Zn(II)Pc LB layers (Inset) The change of absorbance by increasing the number of $\mathrm{Zn}(\mathrm{II}) \mathrm{Pc}$ LB layers.

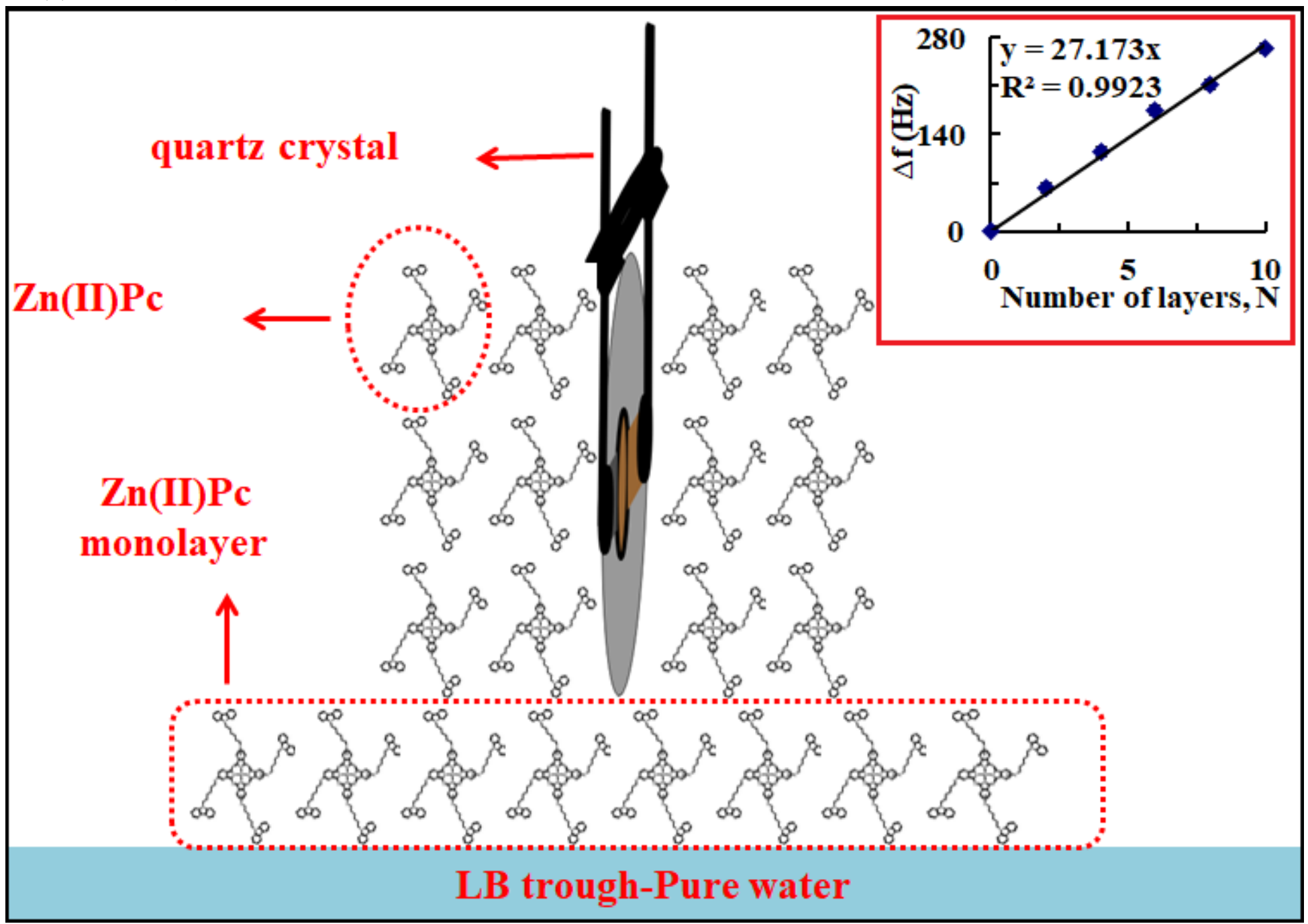

Figure 4

The deposition of Zn(II)Pc monolayer's via LB through (Inset) (a) The mass shift of Zn(II)Pc LB layers. 


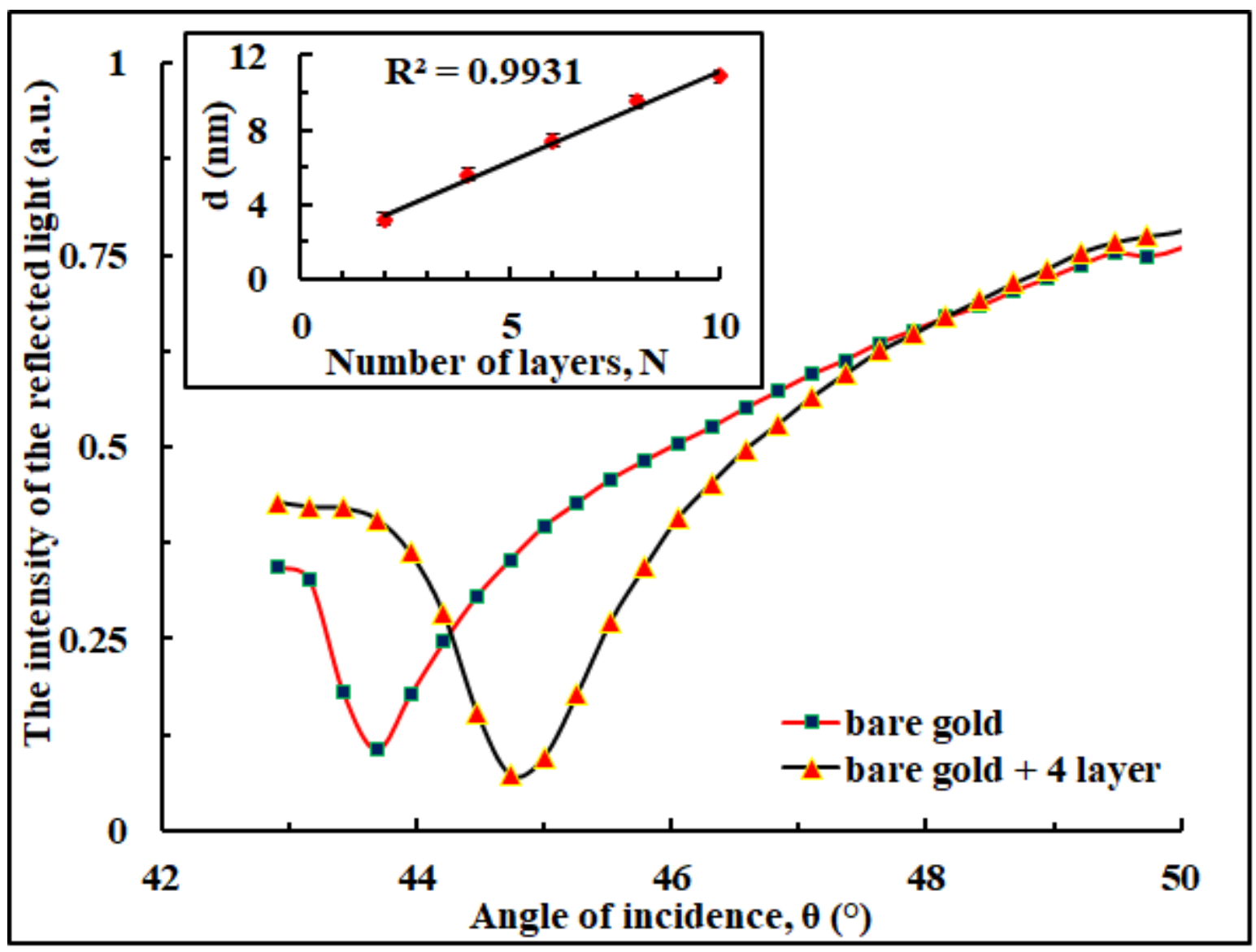

Figure 5

The dots and lines symbolize the measured and fitted data, respectively. (Inset) A linear relationship for the thickness and Zn(II)Pc LB layers. 

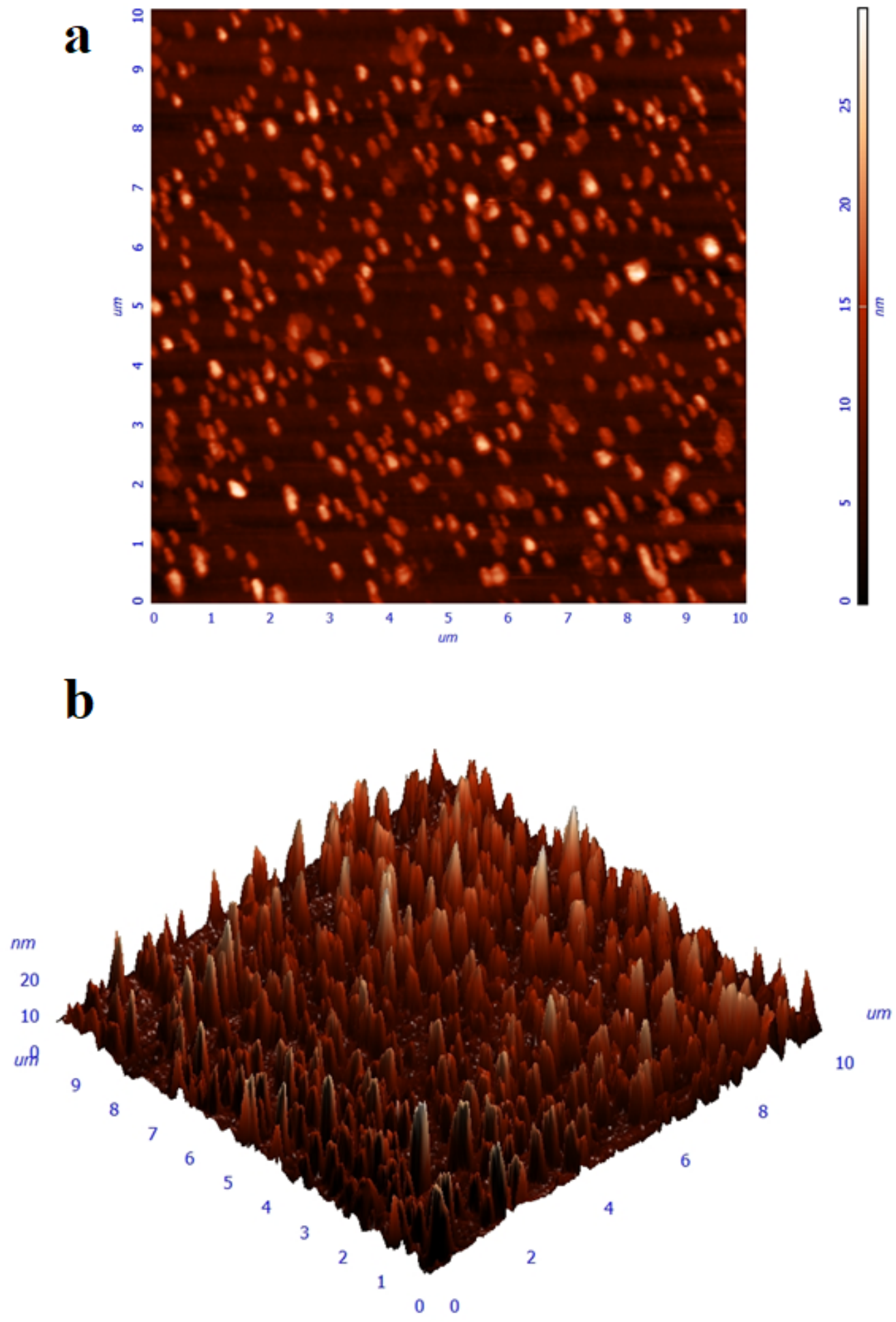

Figure 6

Surface morphology of Zn(II)Pc LB thin film with 2D a) and 3D b) AFM images. 


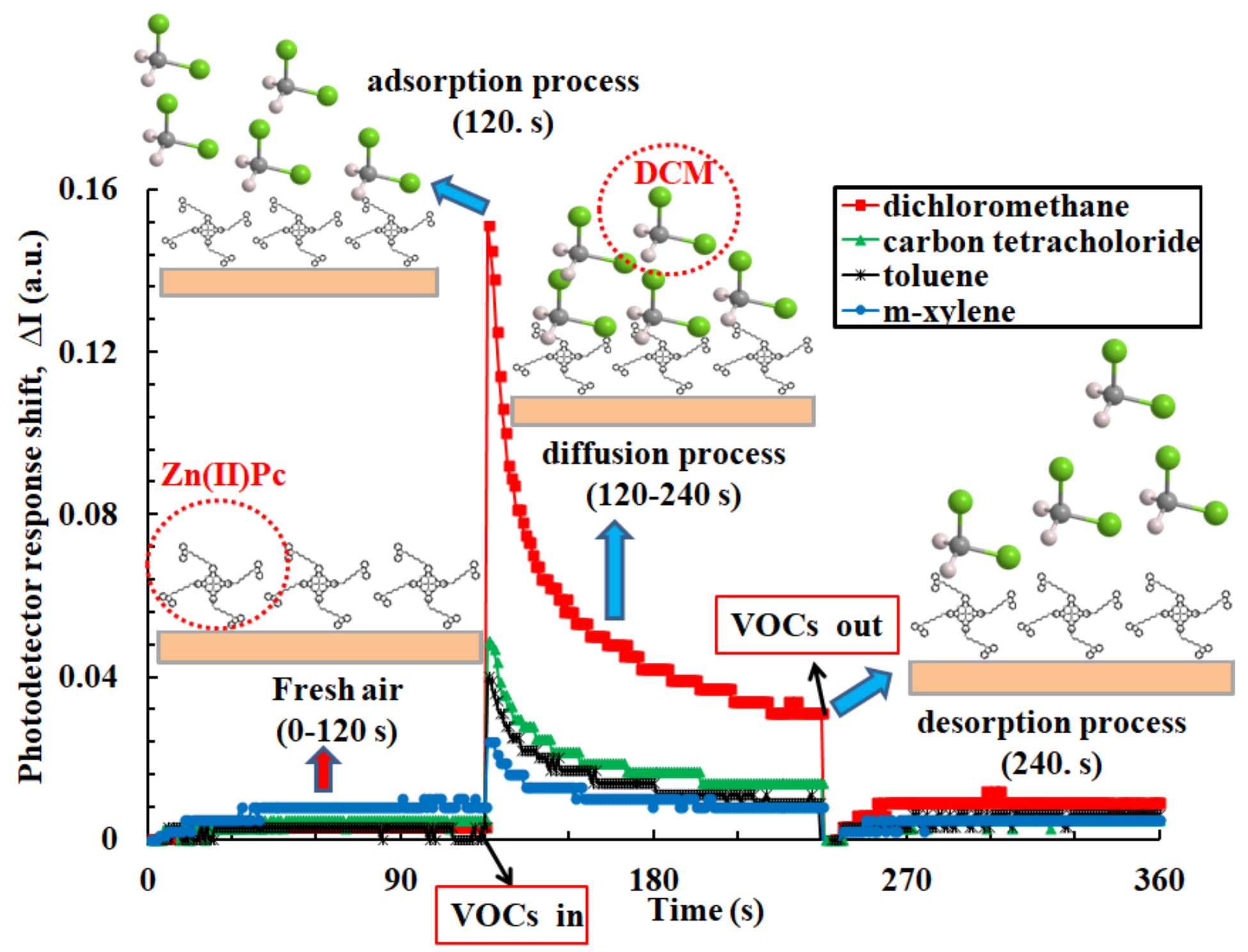

Figure 7

A symbolic demonstration for sensor mechanism and the kinetic response of $\mathrm{Zn}$ (II)Pc-based optical chemical sensor.

\section{Supplementary Files}

This is a list of supplementary files associated with this preprint. Click to download.

- supplementarymaterialsAcikbas12.02.2021.docx 